\title{
IMPLANTAÇÃO DA FERRAMENTA “DISPONIBILIDADE” NO DESGASEIFICADOR À VÁCUO DA CSN*
}

\author{
Carlos Filippe de Sousa Morais ${ }^{1}$ \\ Rodrigo da Silva Magalhães ${ }^{2}$ \\ Antônio Augusto Martins ${ }^{3}$ \\ Matheus Sexto Alexandre Pereira \\ Thiago Aranha da Silva ${ }^{5}$ \\ Jeferson Leandro Klug
}

\section{Resumo}

O software desenvolvido tem como objetivo, mapear o real tempo de operação do $\mathrm{RH}$ da Companhia Siderúrgica Nacional - CSN, identificando os atrasos antes e durante o tratamento de um aço no equipamento. Para isso foi criada uma tela automática que é aberta ao operador toda vez que é identificado atrasos, seja durante a troca de panela (Disponibilidade) ou durante o tratamento do aço (Processo). É possível visualizar em qualquer período desejado o preenchimento dos atrasos através de um relatório e uma interface gráfica interativa gerada pelo software, e com isso tomar medidas capazes de melhorar a produtividade no $\mathrm{RH}$. Os resultados abordados ao longo deste trabalho mostram que a solução de uma pequena parte destes atrasos pode gerar ganhos de produção significativos para a Companhia Siderúrgica Nacional.

Palavras-chave: RH; Produção de aço; Refino secundário.

\section{TOOL DEPLOYMENT "AVAILABILITY" IN THE DEGASSER VACUUM OF CSN}

\section{Abstract}

A software program was developed to control the period of time necessary for operation for the $\mathrm{RH}$ process in Companhia Siderúrgica Nacional (CSN). Aim is to identify delay reasons for the process. For doing that, a window is opened by the software program; steelmakers in this way can register the reasons related to delay, which can happen during ladle change or during steel processing. Through a graphical interface it is possible to perform actions to improve productivity.

Keywords: $\mathrm{RH}$; Steel; Ladle metallurgy.

1 Graduando, Departamento de Engenharia Metalúrgica e de Materiais, Universidade Federal do Ceará, Fortaleza, Ceará, Brasil.

2 Metalurgia, Engenheiro Metalúrgico, Engenheiro de Desenvolvimento, Gerência de Processos da Metalurgia, Companhia Siderúrgica Nacional, Volta Redonda, Rio de Janeiro, Brasil.

3 Metalurgia, Engenheiro Metalúrgico, Coordenador de Projetos Especiais, Gerencia Geral de Processos Siderúrgicos, Gerencia de Processos Metalúrgicos, Companhia Siderúrgica Nacional, Volta Redonda, Rio de Janeiro, Brasil.

4 Bacharel em Tecnologia da Informação, Analista de Tecnologia de Automação, Gerência Geral de Engenharia, Companhia Siderúrgica Nacional, Volta Redonda, Rio de Janeiro, Brasil.

5 Bacharel em Tecnologia da Informação, Analista de Tecnologia de Automação, Gerência Geral de Engenharia, Companhia Siderúrgica Nacional, Volta Redonda, Rio de Janeiro, Brasil.

6 Engenheiro Metalúrgico, Doktor-Ingenieur, Professor Adjunto, Departamento de Engenharia Metalúrgica e de Materiais, Universidade Federal do Ceará, Fortaleza, Ceará, Brasil. 


\section{INTRODUÇÃO}

Este trabalho tem como objetivo a apresentação da ferramenta "Disponibilidade", implantada na Companhia Siderúrgica Nacional - CSN. Com o relatório gerado por esta ferramenta será possível identificar problemas crônicos que impedem uma melhor performance do equipamento, gerando ganhos na produção bastante significativos.

\subsection{Desgaseificação a Vácuo}

O processo $\mathrm{RH}$ é um dos processos de refino secundário, e é caracterizado pela circulação continua de aço através de um recipiente revestido de refratários, no qual se promove o vácuo. Esta circulação é feita através de dois tubos ou pernas, também denominados snorkels, que são imersas no banho metálico. O vaso $\mathrm{RH}$ é então evacuado. A pressão atmosférica, que atua na superfície da panela, causa a elevação do aço para a altura barométrica de aproximadamente 1,45 m, como é ilustrado na figura 1 [1].

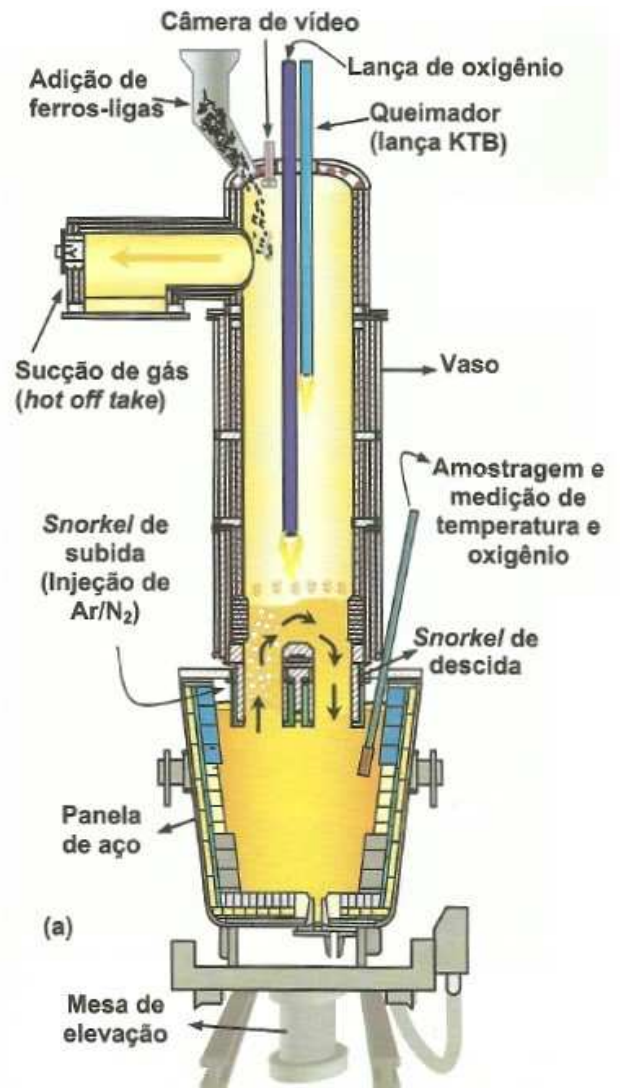

Figura 1. Representação esquemática da estação de refino secundário do tipo $\mathrm{RH}$.

Um dos objetivos da injeção de oxigênio através de lanças posicionadas na parte superior do vaso de tratamento no RH é auxiliar a descarburação. Outras funções importantes deste tipo de acessório são, a de fornecimento complementar de calor através de reações exotérmicas do $\mathrm{Al}$ (adição controlada efetuada para controle térmico) formando $\mathrm{Al}_{2} \mathrm{O}_{3}$ e da pós-combustão de $\mathrm{CO}$ em $\mathrm{CO}_{2}$. No caso da $\mathrm{CSN}$, a tecnologia empregada é a KTB, da Kawasaki Steel Corporation (Kawasaki Top Oxygen Blowing). 
O processo $\mathrm{RH}$ pode ser utilizado para realizar os seguintes tipos de operações:

- redução do teor dos gases $\mathrm{H}$ e $\mathrm{N}$ no aço;

- redução do teor de carbono no aço;

- controle da temperatura do aço líquido;

- ajuste da composição química do aço;

- desoxidação do aço líquido;

- dessulfuração do aço líquido;

- controle da morfologia e remoção de inclusões não-metálicas.

Dentre estas operações, destacam-se como principais a desgaseificação do $\mathrm{H}$ e $\mathrm{N} \mathrm{e}$ a descaburação. Considera-se que o objetivo primordial da desgaseificação é produzir um aço líquido com o mínimo possível de gases dissolvidos no banho. $O$ processo $\mathrm{RH}$ permite que, através da aplicação de vácuo, ocorra redução do teor de gases para valores abaixo de 2 ppm para hidrogênio e abaixo de 20 ppm para 0 nitrogênio. Estes são valores indicativos, podendo ser atingido níveis menores com um controle mais rigoroso do processo.

O processo de desgaseificação à vácuo nos sistemas que realizam a recirculação do aço em um vaso acima da panela de aço líquido, normalmente segue as etapas apresentadas a seguir:

- a panela de aço líquido é posicionada na estação $\mathrm{RH}$;

- é realizada a introdução dos snorkels no banho de aço metálico;

- é promovida a redução de pressão no vaso superior, de tal forma que o banho de aço líquido seja forçado a subir, atingindo uma altura em torno de 1,40 $\mathrm{m}$ acima do nível da superfície original;

- o gás inerte (normalmente utiliza-se argônio) é injetado na parte inferior do primeiro tubo, próximo à superfície de aço na panela; a injeção de gás inerte pode ser iniciada um pouco antes para impedir a obstrução dos bicos de injeção; este tubo é chamado de snorkel de subida, e consequentemente o outro de snorkel de descida.

- o gás injetado sobe e deste modo causa a aceleração do aço líquido no snorkel de subida, além de provocar a redução da densidade do aço líquido, o que auxilia no deslocamento para cima do mesmo;

- forçado pelo aumento da temperatura, decréscimo da pressão e pela liberação dos gases do aço na parte superior do tubo, o metal fundido desintegra em pequenas gotas dentro do vaso, retorna para a superfície e desce pela outra perna do snorkel, promovendo o movimento circulatório de metal líquido.

Ao final do processo, feita a medição de composição química e de temperatura, e estas estando dentro da margem pré-estabelecido, à panela é encaminhada para o lingotamento contínuo.

\section{MATERIAIS E MÉTODOS}

A ferramenta desenvolvida, "Disponibilidade", tem como objetivo mapear dentro do tempo calendário o real tempo de utilização do Desgaseificador a Vácuo $\mathrm{RH}$ da CSN. O software foi implantado no sistema de Nível 2 do equipamento e tem como base os eventos enviados pelo Nível 1. O software reconhece de forma automática 0 inicio e fim do tratamento das corridas no $\mathrm{RH}$ (comando executado pelo operador no nível 1) e as movimentações do carro panela (sensor instalado na entrada do trilho do equipamento por onde passa a panela). Quando uma corrida é iniciada no $\mathrm{RH}$ verifica-se o tempo decorrido desde o último tratamento e, caso esse tempo seja superior ao considerado aceitável (20 minutos), é aberta uma tela automática no Modelo de Nível 2 onde o operador deve justificar o motivo do equipamento não 
estar operando. Os motivos são pré-definidos no software, podendo ser incluídos, retirados ou modificados a qualquer momento. Uma outra funcionalidade do software é verificar se os tempos padrão de tratamento para cada tipo de aço estão sendo seguidos. Qualquer atraso que exceda o tempo de processo do grau de aço deve ser justificado pelo operador também através de motivos pré-cadastrados. Dessa maneira consegue-se mapear de forma precisa o real tempo de operação do $\mathrm{RH}$, os atrasos durante o tratamento da corrida e os motivos de sua não utilização. Os resultados podem ser visualizados via interface gráfica em qualquer período desejado. Através dos dados é possível identificar e quantificar os problemas crônicos que impedem uma melhor performance do equipamento permitindo que ações de melhoria/bloqueio sejam implantadas.

\section{RESULTADOS E DISCUSSÃO}

O software "Disponibilidade" é composto por dois programas. O "Disponibilidade" que atua durante as movimentações de panela (chegada e saída) e o "Processo" que atua durante o tratamento do aço, ou seja, durante o tempo de evacuação do equipamento.

A panela é levada ao equipamento por meio de um carro panela que se encontra sobre um trilho. $O$ carro panela é dirigido para o equipamento e em um determinado ponto do trilho existe um sensor de movimento que identifica a chegada da panela no equipamento. Esta informação de chegada de panela feita pelo sensor é comunicado e registrado de forma direta e automática no Nível 2. Da mesma forma ocorre quando da retirada da panela do equipamento após o tratamento do aço. $\mathrm{O}$ sensor comunica e registra diretamente no Nível 2. Essa comunicação de chegada e saída de panela são os parâmetros utilizados para a identificação de atrasos decorrentes das trocas de panela, ou seja, o "Disponibilidade". O tempo aceitável para a saída de uma panela e chegada de uma outra é de 20 minutos. Quando o Nível 2 identifica a saída de uma panela, começa a contagem para a chegada da próxima panela. Após a chegada e registro dessa outra panela no Nível 2, é feita de forma automática pelo software a contagem total da troca de panela. Se, caso a troca seja inferior aos 20 minutos é entendido como uma troca sem atraso, porém se essa troca de panela for superior a 20 minutos, então é aberta uma tela automática (figura 2) para o operador para que ele possa colocar o motivo do atraso, que pode ser decorrente de vários motivos.

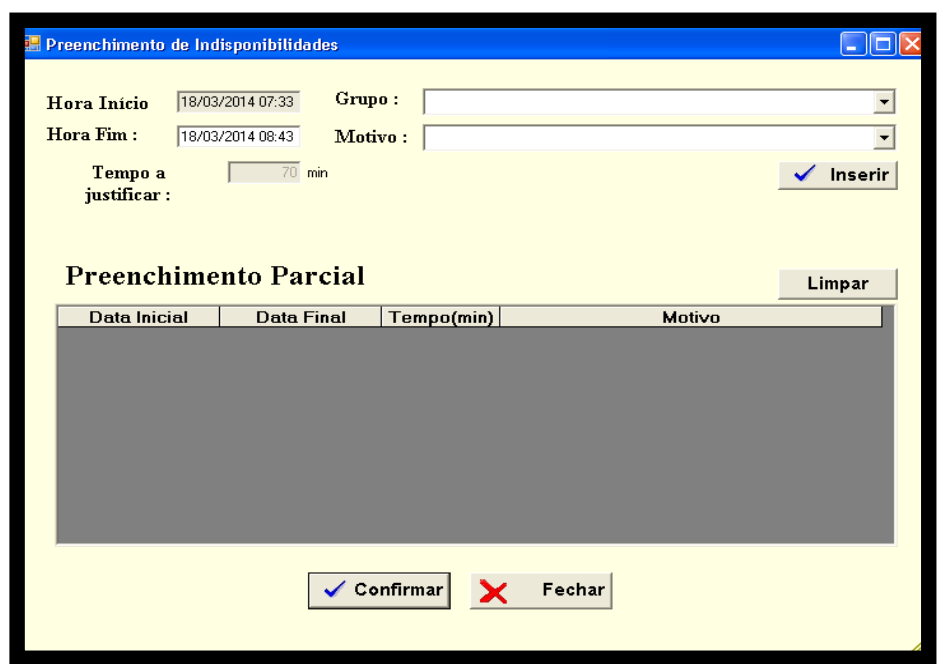

Figura 2. Tela de preenchimento do "Disponibilidade". 
Como se pode perceber, a tela aberta automaticamente para a justificativa do atraso é composto pela hora início (saída de panela) e hora fim (chegada de uma nova panela) e o tempo total a ser justificado. Dados de grupo e motivo também devem ser preenchidos de acordo com a natureza real do atraso. Estes grupos e motivos são pré-cadastrados no software pela engenharia e são dispostos por categorias, por exemplo:

- Grupos:

- Parada programa operação

- Parada programa manutenção

- Parada de emergência de manutenção elétrica

- Parada de emergência de manutenção mecânica

- Parada de emergência externa

Dentro de cada grupo haverá motivos condizentes na categoria especificada do grupo, por exemplo, no grupo parada programa operação:

- Motivos:

- Adequação de tempo entre liberação e abertura

- Atraso ponte GOS - Atendimento ao RH

- Demolição das pernas

- Deskuling

- Limpeza da plataforma móvel

- Limpeza das pernas

Após a inserção do grupo e do motivo condizente com a justificativa do atraso, 0 operador confirma e a tela é fechada. Com isso se dá por finalizado o preenchimento do "Disponibilidade"

O "Processo" se enquadra em outro programa do software. Ele tem por objetivo identificar os atrasos durante a evacuação, ou seja, durante o tratamento do aço.

Para que o tratamento do aço seja iniciado é necessário que o operador acione o comando de inicio de vácuo no Nível 1, essa informação é transmitida diretamente para o Nível 2, onde funcionará como uma variável no software para identificação do inicio de vácuo. Após o término do tratamento do aço o operador acionará o comando de fim de vácuo no Nível 1 e em comunicação com o Nível 2 a informação é repassada para o software. Estas variáveis são as responsáveis pela mediação de atrasos do "Processo".

Existe um tempo padrão de tratamento (Tempo de evacuação) para cada tipo de aço, então o software identifica qual o tipo de aço a ser tratado e qual o seu tempo padrão de tratamento, e é acrescentada uma tolerância de 2 minutos a este tempo em virtude de possíveis atrasos inerentes ao processo e que não são relevantes o seu registro. Por exemplo:

- Aço 2710

- Tempo padrão de tratamento: $X$ minutos

- Tolerância: 2 minutos

Após o tratamento do aço, e finalização da evacuação o software analisa o tempo total gasto na evacuação e se este tempo for superior a $(X+2)$ minutos, é aberta uma tela automática no Nível 2 (figura 3) para o operador fazer a justificativa do atraso. 
國 Preenchimento das Indisponibilidades do Processo

\begin{tabular}{c} 
Corrida: \\
\hline 4A2431 \\
Tempo de \\
Vácuo Real
\end{tabular}

Grupo :

ácuo Real :

Tempo de Vácuo

Padrão:

25

Diferença

$\longdiv { 2 7 3 }$

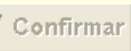

Figura 3. Tela de preenchimento do "Processo".

Percebe-se que as informações de corrida, tempo total de vácuo, tempo de vácuo padrão e a diferença são lidas na tela de forma automática. E o preenchimento é feito de forma análoga ao "Disponibilidade" onde é contido grupos e motivos condizentes agora com o "Processo", portando diferentes dos "Disponibilidade".

\subsection{Histórico e Interface Gráfica}

O software dispõe de um histórico de todos os eventos realizados no $\mathrm{RH}$ da CSN, bastando apenas que seja selecionado o período de interesse a ser consultado. Os históricos do "Disponibilidade" e do "Processo" são independentes, como mostra as figuras 4 e 5 .

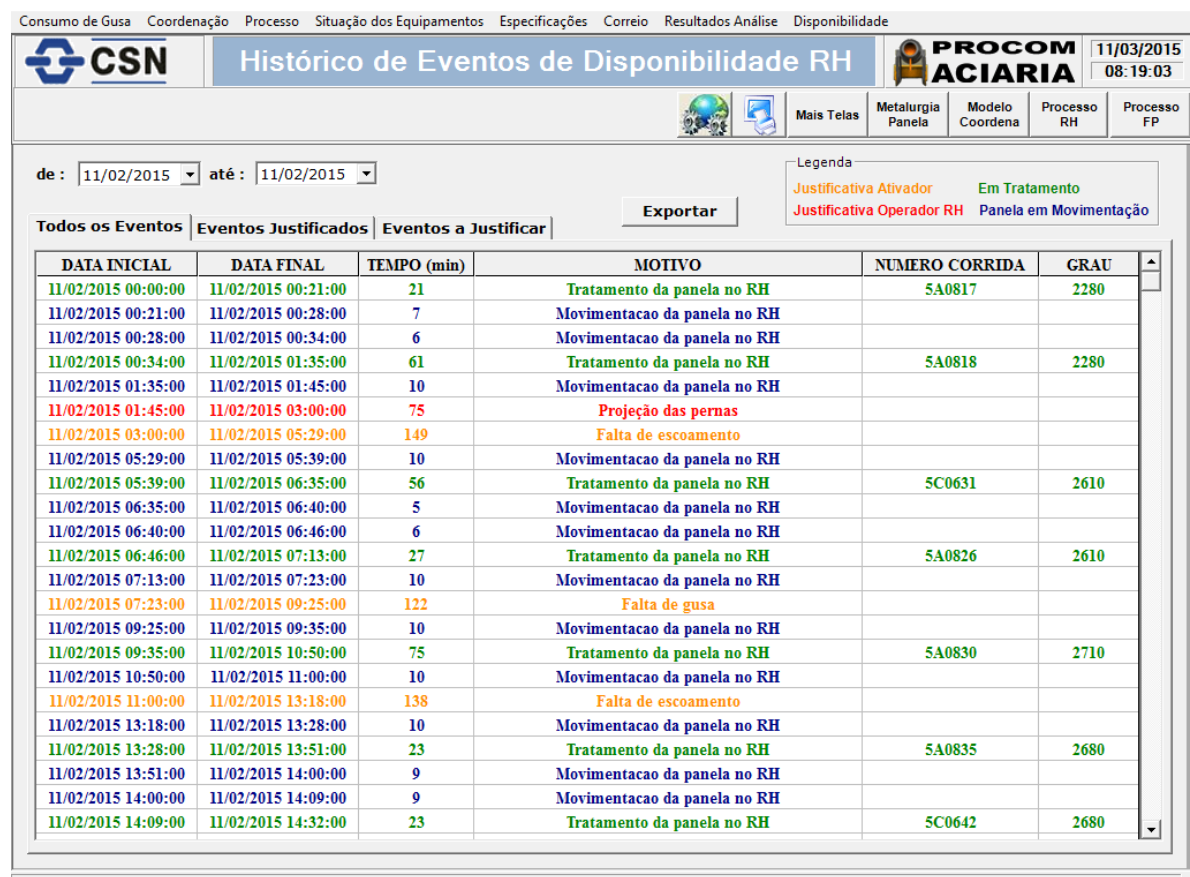

Figura 4. Tela do histórico de eventos do "Disponibilidade". 


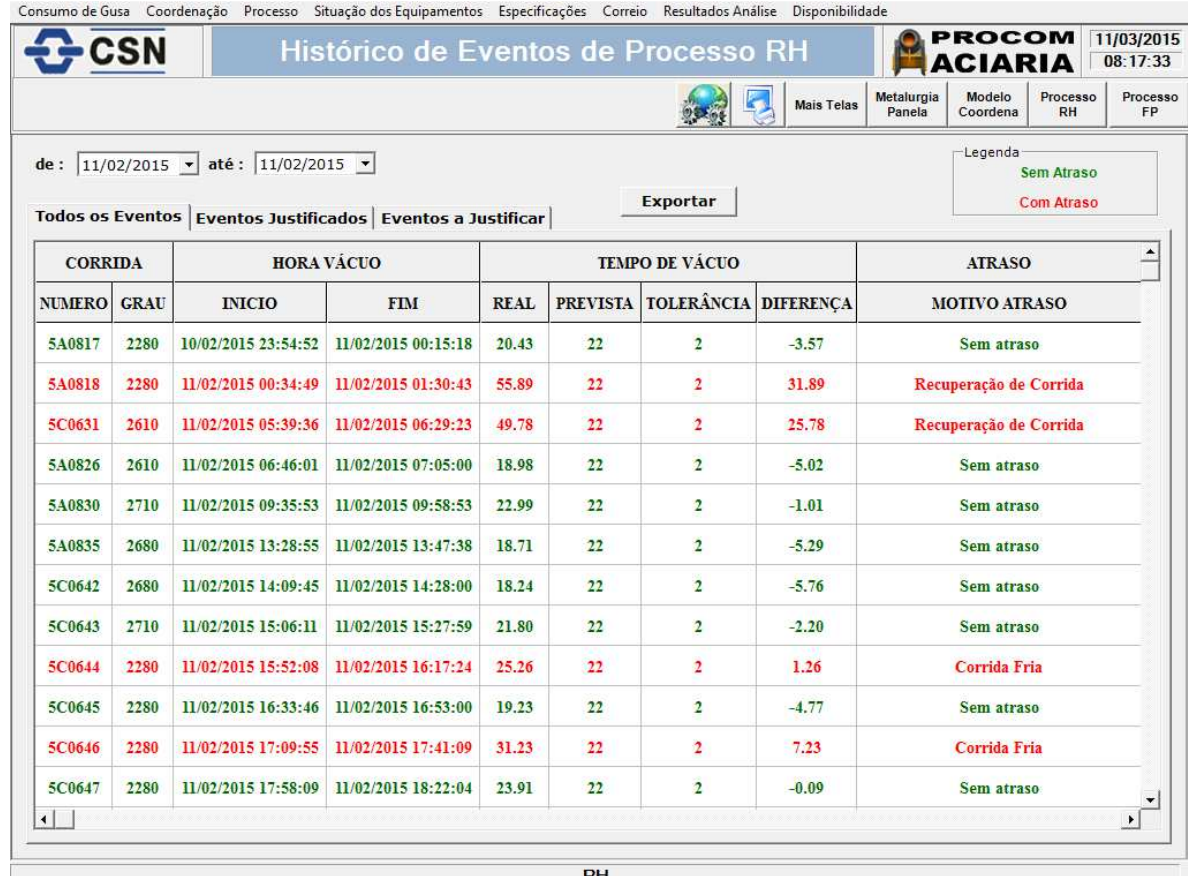

Figura 5. Tela do histórico de eventos do "Processo".

$\mathrm{Na}$ figura 4, são listados os eventos do dia de interesse. Percebe-se que estes eventos são diferenciados por cores, como mostra a legenda do "Disponibilidade". A movimentação de panela é caracterizada pela cor azul, quando essa movimentação de panela apresenta atraso, um evento em vermelho aparece entre as movimentações de panela com a justificativa preenchida pelo operador na tela automática. Quando esse atraso aparece na cor amarela, significa que o preenchimento não foi feito pelo operador do $\mathrm{RH}$, e sim, pelo programador de corridas da aciaria. Toda vez que o programador de corridas da aciaria fizer o preenchimento é devido uma tela automática que aparece para ele em decorrência do equipamento do $\mathrm{RH}$ estar disponível para tratamento de corridas, e por alguma razão nenhuma programação foi direcionada ao equipamento. Para isso, o operador de RH possui um motivo designado "Disponível" indicando esse fato, que gera a tela automática para o programador de corridas da aciaria. No "Processo" (figura 5) os eventos em verde caracterizam-se pelo não atraso durante o tratamento e os eventos em vermelhos indicam atrasos.

Além do histórico, a ferramenta é composta também por uma interface gráfica bastante interativa que mostra os eventos justificados, tanto para o "Disponibilidade" quanto para o "Processo" no período desejado. 


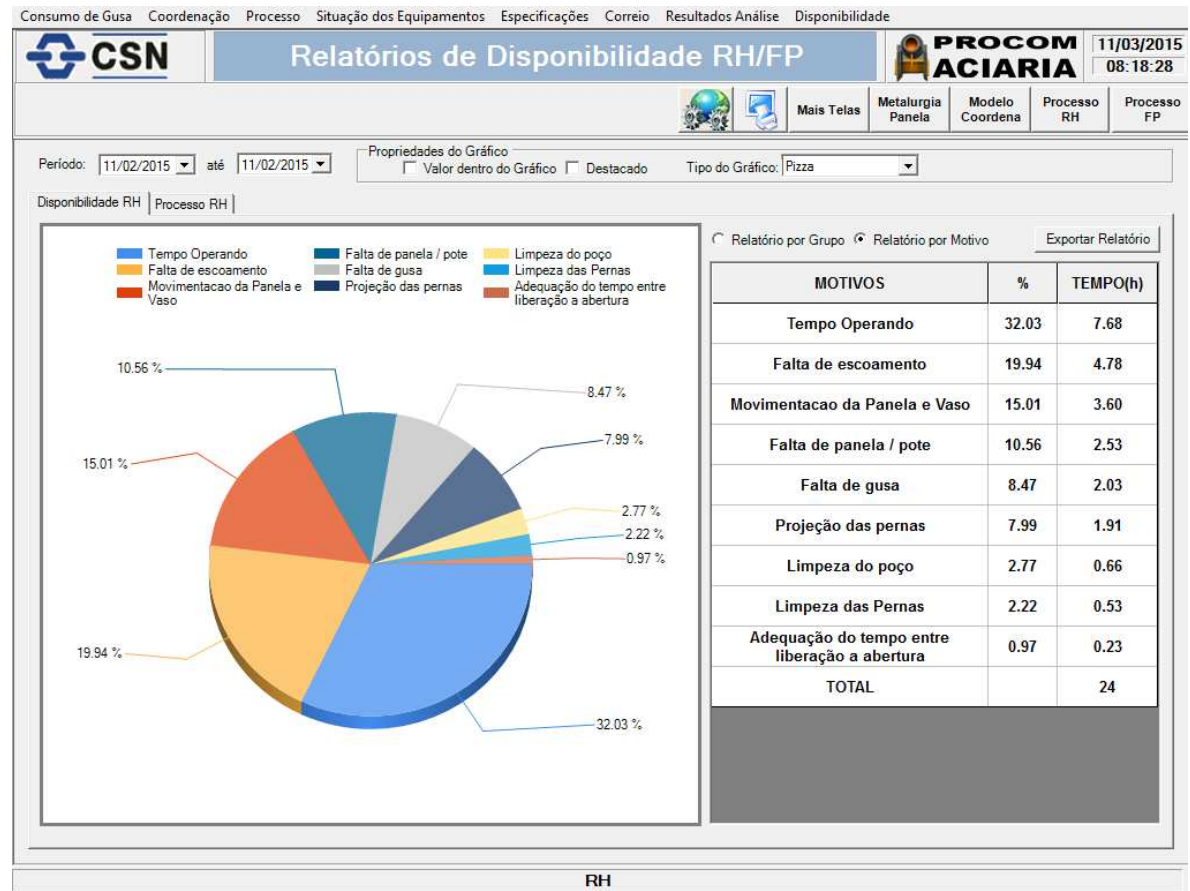

Figura 6. Tela do relatório do "Disponibilidade".

Utilizando o histórico e a interface gráfica do software é possível analisar em um determinado período desejado quais foram os atrasos anormais que o $\mathrm{RH}$ da CSN sofreu e que por conta disso o equipamento ficou impossibilitado de operar.

Atrasos devido a motivos necessários ao equipamento não são levados em consideração em um possível ganho de produção, visto que são necessários para a continuidade do funcionamento do equipamento. Por exemplo: Tempo operando, movimentação de panela, manutenções preventiva, programada e elétrica, limpeza, demolição e projeção de pernas, troca de vaso, deskulling, entre outros.

\section{Ganho Estimado em Número de Corridas}

1. Quantidade de horas em que o equipamento ficou parado em um determinado período;

("Disponibilidade" + "Processo");

2. Tempo total gasto para a conclusão de 1 corrida;

(Tempo de Evacuação + Tempo de troca de panela);

3. Objetivar uma porcentagem de redução das horas em que o equipamento ficou parado no periodo;

4. Calcular o ganho de horas no periodo em decorrência da redução;

5. A quantidade de corridas ganhas no periodo é encontrada relacionando o tempo ganho com a redução objetivada e tempo total gasto para a conclusão de 1 corrida.

Número de Corridas $=$ Ganho de horas no período Tempo total gasto 1 corrida

Figura 7. Ganho estimado em número de corridas. 


\section{CONCLUSÃO}

Com a implantação do "Disponibilidade" e a análise dos dados fornecidos pelo software é possível identificar e quantificar os problemas crônicos que impedem uma melhor performance do equipamento permitindo que ações de melhoria/bloqueio sejam implantadas. Feitas essas melhorias, certamente irá haver um ganho na produção de aço que será convertida em ganho financeiro para a empresa.

\section{Agradecimentos}

Agradeço a CSN, que me possibilitou a participação neste projeto e a enriquecer o meu conhecimento teórico através da vivência prática em uma indústria de grande porte. A equipe de operadores do RH da CSN pela compreensão e participação efetiva para o sucesso da implantação do "Disponibilidade". Ao Rodrigo, Augusto, Thiago e Matheus pela confiança e os valorosos conhecimentos repassados durante o período de vivência na CSN. Ao professor Jeferson pelo conhecimento teórico repassado e a ajuda na construção deste trabalho descritivo.

\section{REFERÊNCIAS}

1 Rizzo, Ernandes Marcos da Silveira. Introdução aos Processos de Refino Secundário dos Aços. São Paulo. ABM; 2006. 